\title{
British Industries Fair
}

\begin{abstract}
$\mathrm{A}^{\mathrm{s}}$ year succeeds year, the visitor to the British Industries Fair, on the lookout for exhibits of scientific interest, finds the range and variety ever greater. Looking back over a period of years, he cannot fail to be struck with the emergence from time to time of entirely new industries, the fruits of scientific research and discovery. Not only so, but also the scope of long-established industries is being continually widened, as new products or new applications of old products are discovered. As ons goes through the specifically scientific exhibits or exhibits possessing some scientific interest, one can picture the character and the extent of the prolonged scientific research that must have preceded the eventual production of the materials or articles exhibited.
\end{abstract}

The chemical industry in particular each year brings before the visitors to the British Industries Fair new products and long-established products manufactured to a still higher degree of purity, to meet modern needs. It may also be remarked that the art of displaying the exhibits seems to improve each year, although the writer noticed in a few cases a tendency, perhaps, to elaborate the framework at the expense of the exhibit framed. On the whole, however, this year marked a distinct advance in what may be called the informative and educative value of the exhibits. For example, this year's main stand of Imperial Chemical Industries, Ltd., at Olympia, consisted of a well-set-out diagrammatic exhibit dealing with the production of ammonia and its varied uses. Displays dealing with water sterilization, the preparation of rubber latex, refrigeration and metal production exhibited the uses of ammonia in its anhydrous form. The uses of ammonia liquor were indicated by references to the manufacture of cuprammonium silk, to toilet ammonia preparations and to laundry and textile processes. Among other sections of this comprehensive exhibit were those dealing with the uses of ammonia converted to cyanide-fumigation by hydrocyanic acid, gold extraction and case hardening -and of ammonia as urea in the manufacture of plastics and in the pharmaceutical trade.

On the stand of Boots Pure Drug Company, Ltd., was a large diagrammatic chart, showing stages in the manufacture of fine chemicals from coal tar. Among organic reagents for metals, Hopkin and Williams, Ltd., showed resacetophenone (dihydroxyacetophenone), a reagent for iron, and dimercaptothiodiazole, a reagent for bismuth, which has now been recommended for the determination of lead tetraethyl in petrols. They also showed for the first time a group of fluorescent indicators, which are recommended for the determination of acidity or alkalinity of strongly coloured solutions which inhibit the use of visual indicators.

Turning to the grouped exhibits of the scientific instrument manufacturers, these, as in the last fow years, formed one of the outstanding features of Olympia. It is impossible within the limits of this article to do more than direct attention to a few of the novel products shown this year. Ross, Ltd., exhibited a very remarkable wide-angled survey lens, recently produced. It has an angle of $96^{\circ}$ and consists of a five-lens system, in which the separation between the component lenses is $1 / 1000$ in. The lenses are not cemented but held in position by special clips, in order to avoid strain that might be set up by the use of a cemented lens at high altitudes where very low temperatures prevail. Moreover, the system is mounted in stainless steel having a coefficient of expansion equal to that of the glass, so as to avoid any possibility of strain or deformation due to differential temperature changes. As to the performance of this lens, a photograph was exhibited taken from a height of $20,000 \mathrm{ft}$. covering 40 square miles of London with one exposure, all the streets and main landmarks being easily recognized by the naked eye. This lens is a remarkable achievement, of which the British optical industry may well be proud. It is made of $3 \frac{1}{2}$ in. focus upwards and is priced from $£ 250$ upwards. Ross, Ltd., also showed a new, extremely lightweight prism binocular with extra-wide field. The effective diameter of the object glass is $30 \mathrm{~mm}$. with a real field of view of $9^{\circ}$ and an apparent angle of $63^{\circ}$, and the instrument is provided with central focusing by screw adjustment.

Charles Baker showed a new micrometer measuring microscope, with a travel of $300 \mathrm{~mm}$. (12 in.), reading to $0.01 \mathrm{~mm}$. direct and by estimation to $0.0025 \mathrm{~mm}$. The microscope is mounted on two accurately ground, stainless steel bars on the kinematic principle. The stage is also mounted on the kinematic principle and has coarse and fine adjustment in the vertical direction.

Cooke, Troughton and Simms, Ltd., showed a new geodetic level designed for the Ordnance Survey in conjunction with Major Hotine of that Survey. The body of the telescope is made of metal having the same coefficient of expansion as that of the glass incorporated. The focal length is $13 \mathrm{in.}$ and the aperture of the object glass 2 in. The main spirit level-a split bubble is read in the field of view of the telescope by the coincident method.

E. R. Watts and Son, Ltd., exhibited a new theodolite, having the following novel features: short but powerful telescope, glass instead of metal circles, the use of an optical micrometer for reading the subdivisions, an optical plummet incorporated in the body of the instrument, and the complete enclosure of the circles and optical system.

Among the exhibits of R. and J. Beck, Ltd., was a combined binocular and monocular microscope, having an inclined eyepiece. It contained means for varying the inter-ocular distance and for the changeover to the monocular without dismantling the lenses. They also showed a new model of the Hartridge reversion spectroscope, designed specially for the physicist. It has a symmetrical slit and is graduated to read direct into Angström units.

Among the exhibits of W. Watson and Sons, Ltd., was an apparatus known as the 'library reader'. By means of a camera a photographic record of, say, a 500-page book can be taken on only $30 \mathrm{ft}$. of standard cine film. The film can then be projected on to a screen to be read conveniently. One purpose of this apparatus is to render accessible to serious students unique manuscripts and precious early editions of books possessed by libraries, where it would be inconvenient to allow the actual books to be used. 
Adam Hilger, Ltd., showed a photometric colour comparator. Its main use is for the maintenance of colour uniformity or the matching of specimen colours in various industries. It makes use of polarizing laminæ, the planes of polarization of which are mutually perpendicular. It is not suggested that this instrument can take the place of a colorimeter of such precision as the trichromatic colorimeter, or of an accurate spectrophotometer, but for the diagnosis of colour faults and for colour standardization within the factory it is claimed to be of great practical value. Messrs. Hilger also showed a projection spectrum comparator. This instrument projects the images of two spectrograms-the spectrum to be interpreted and the standard spectrum-in juxtaposition upon an easily viewed screen, and so avoids monocular observation through an eyepiece. This firm also showed a spectrograph having a flat focal field, so that no adjustment of focus is required for any part of the spectrum. An ineidental advantage of the flat photographic plate that may consequently be used is that the thickness of the glass does not matter and the spectrograph is no longer restricted to the use of thin plates.

The most prominent feature of the scientific instruments exhibit, and the one, perhaps, which aroused most interest in the visitors, was the antiaircraft predictor. This instrument computes mechanically for anti-aircraft purposes the position of an approaching target, such as a hostile bomber. It will be realized that the speeds of modern aircraft are such that it may be necessary to direct the gun as much as two miles ahead of the path of the bomber, if the projectile is to hit the 'target'. The target must be visible to the observer and, therefore, at night must be 'caught and held' by the searchlight. The telescope of the predictor is then laid on to the target and follows it, and as it does so the instrument shows automatically the position and other data required and feeds the gun crew automatically and simultaneously with all the necessary information for firing, including even directions for the adjustment of the shell fuse. To the lay visitor it must have seemed almost like black magic.

\section{Microtechnique in Organic Chemistry}

\begin{abstract}
A SURVEY of the most important advances in organic chemistry during the last ten or fifteen years shows that these deal very largely with the chemistry of naturally occurring produets. Perhaps the most striking developments are the determination of the structure of the principal vitamins, the very existence of which was debatable fifteen years ago, and the olucidation of the nature of the sex hormones and of the plant growth substances (auxins). No less important, if less spectacular, work has been done on new alkaloids, plant pigments, insecticides and triterpenes.

A point which cannot fail to strike the observer is that the quantities of material available for these investigations are of necessity extremely small. 'Thus the total amount of auxin used by Kögl in the elucidation of its structure was of the order of one gram, yet the molecule of this compound contains eighteen carbon atoms ; and the majority of the other hormones and vitamins are equally or more complex.

These investigations were only made possible by the development in the course of the last two decades of a number of new experimental methods, which have revolutionized the technique of organic chemistry; thus it is now possible to carry out analyses on quantities of about $1 / 50$ of those formerly required, whilst the degree of accuracy and reliability attainable is definitely greater.
\end{abstract}

In view of what has been said, the symposium on microtechnique held by the Chemical Society on March 2 was particularly timcly and a number of new advances were discussed by specialists.

Prof. I. M. Heilbron opened the discussion and gave a general survey of the methods available to the investigator. Of these, quantitative analysis is perhaps the most important; it is to-day possible to carry out exact estimations of carbon and hydrogen, nitrogen, sulphur, halogens and the metals using $2-3 \mathrm{mgm}$. of material. Molecular weights can be rapidly determined on even smaller amounts of material by Rast's cryoscopic method, and functional groups, such as acetyl, methoxyl and $N$-methyl, can all bo determined on quantities of not more than $5 \mathrm{mgm}$. Active hydrogen can be estimated by the micro-Zerevitinov method, while the modern methods of titration are extremcly accurate and can be successfully applied to such compounds as the resin acids and the sapogenins of the $\mathrm{C}_{30}$ groups. Finally, the degree of unsaturation can be quantitatively estimated and an apparatus for this purpose, designed for quantities of $1 \mathrm{mgm}$. or loss, was described by Dr. H. Jackson. An improvement of Pregl's microcombustion apparatus, in which rubber connexions have been entirely eliminated without making the apparatus fragile, was demonstrated by Mr. W. F. Boston.

Absorption spectra provide a purely physical method of observation which can be of the greatest service to the chemist, as Prof. Heilbron showed on several striking examples, and necessitates only minute amounts of material. The method is particularly valuable for ascertaining the number and arrangement of unsaturated centres in the molecule; it is indispensable when dealing with the vitamins of the $\mathrm{A}$ and $\mathrm{D}$ groups, carotenoids, ete. Thus, the constitution of myxoxanthin, $\mathrm{C}_{40} \mathrm{H}_{54} \mathrm{O}$ was established by Heibron and Lythgoe with considerable certainty on the basis of its absorption spectrum although less than a gram of the pure substance was available. The existence of a now vitamin peculiar to the liver oils of freshwater fish was discovered by the spcctrographic method and later confirmed by chemical means. At times it is also possible to decide between two alternative types of ring structure, as in the recent instance of $\alpha$-tocopherol ; the extinction coefficient of this compound was found by John to be consistent, with a chroman and not a coumaran skeleton.

The determination of molecular weights of solids can be carried out on less than $1 \mathrm{mgm}$. of material, provided one or two good crystals are available, by an X-ray method which was described by Mr. D. Riley working with Miss D. Crowfoot. The method depends on the accurate determination of certain constants, namely $p$, the density of the solid, $V$, the volume of the unit cell in the crystal, and $n$, tho 